Original Article

\title{
FACIAL ARTERY ON FACE - A STUDY ON SOUTH INDIAN CADAVERS AND SPECIMENS
}

\author{
Lydia S. Quadros ${ }^{1}$, Arathy Babu² \& Antony Sylvan D'souza ${ }^{3}$ \\ ${ }^{1}$ Lecturer, ${ }^{2}$ Post Graduate, ${ }^{3}$ Professor \& Head, Department of Anatomy, Kasturba M edical College, \\ M anipal University, Madhavnagar, M anipal, Karnataka, India - 576104. \\ Correspondence \\ Lydia S. Quadros \\ Department of Anatomy, Kasturba Medical College, Manipal University, Madhavnagar, M anipal, Karnataka, India - 576104 \\ E-mail : lidibudy@gmail.com
}

\begin{abstract}
:
Context : Facial artery is usually the main artery supplying the face. It gives three named branches on the face, the inferior labial, the superior labial and the lateral nasal and continues as the angular artery. Face is also supplied by the transverse facial artery and the arteriesaccompanying the cutaneousnerves.
\end{abstract}

Aim: In the present study, variations of facial artery on face were observed.

Settings \& design: Department of Anatomy, Kasturba M edical College, Manipal.

M aterial \& method: The present study was performed on 38 males and 12 females' formalin-fixed hemi-faces. Diameter of facial artery was noted at two specific pointsusing a fine microcaliper.

Results: The variations were divided into 3 categories. Out of 38 male hemi-faces, $100 \%$ right and $78 \%$ left hemi-faces belonged to type I category; $22 \%$ left hemi-faces belonged to Type III category. Out of 12 female hemi-faces, $80 \%$ right and $80 \%$ left hemi-faces belonged to Type I category, $18 \%$ left hemi-faces belonged to Type II category and $20 \%$ right and $2 \%$ left hemi-faces belonged to Type III category. Premasseteric branch was observed in 4 hemi-faces; a duplex with a prominent lateral angular branch was observed in 4 hemi-faces and anenlarged transverse facial artery was seen in 2 hemi-faces. The diameter of facial artery at its origin and at the antero-inferior angle of masseter musclewas larger in males.

Conclusion:This study shows that the variations in the branches and the diameter of the facial artery were relatively larger in males when compared to females.

Keywords : Angular artery, facial artery, inferior labial artery, lateral nasal artery, premasseteric branch, superior labial artery

\section{Introduction:}

Facial artery attributes to high vascularity of face which helps in increasing the ability of the skin to heal rapidly and gain excellent results during plastic facial surgery. Facial artery, a branch of external carotid artery, is given off just above the tip of greater cornu of hyoid bone. After its course in the neck region, it enters the face by winding around the lower border of the body of the mandible at the antero-inferior angle of masseter muscle. It runs a sinuous course to accommodate to Access this article online
Quick Response Code

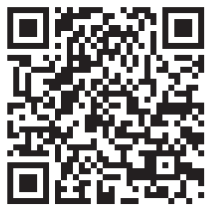
the mobility of the structures through which it passes. ${ }^{[1]}$ Facial artery gives numerous named and unnamed branches on face. The three named branches are Inferior labial, Superior labial and lateral nasal. After giving off the lateral nasal branch, the facial artery continues as angular artery and anastomoses with a branch of internal carotid artery.

Bayram et.al $(2010)^{[2]}$ studied the variations of facial artery in the fetuses. He divided the variations into three categories. Type I category - facial artery terminated as angular artery, Type II category - facial artery terminated as superior labial artery, Type III category - facial artery terminated asinferior labial artery.

Loukas et.al $(2006)^{[3]}$ divided the variations of facial artery under five categories. Type A- facial artery terminated by bifurcating into superior labial and lateral nasal arteries (47.5\%); in Type B-facial artery terminated as superior labial and lateral nasal with the lateral nasal continuing as superior alar artery (38.7\%); in Type C- facial artery terminates as superior labial artery (8.4\%); in Type D- 
angular artery arises directly from facial arterial trunk rather than as a termination of lateral nasal, with the facial artery ending as superior alar artery (3.8\%); in Type E- facial artery terminated as a rudimentary twig without providing any significant branches (1.4\%). He specially emphasized on the superior labial artery.

Premasseteric branch of facial artery which was first described by Adachi in $1928^{[4]}$ is likely to be injured causing severe bleeding during maxillofacial surgeries. A study conducted by Magden et.al $(2009)^{[5]}$, on the premasseteric branch, suggested that in $3 \%$ cases the diameter of premasseteric branch was larger than the facial artery.

In a study conducted by to Lohn et.al (2011) ${ }^{[6]}$ on 201 facial arteries, suggested that, the facial artery predominantly terminated as lateral nasal artery in $49 \%$ of cases and facial artery was undetectable with transverse facial artery dominance in $5 \%$ cases.Tubbs et.al $(2005)^{[7]}$ reported a case of enlarged transverse facial artery with the agenesis of facial artery.

The knowledge of such variations of facial artery becomes more important during maxillofacial, rhinoplastic and orofacial surgeries. It is also important in performing the facial artery musculo-mucosal flap ${ }^{[8]}$ which has been used for the reconstruction oforonasal fistulas ${ }^{[9]}$ and closure of soft tissue defects in mandibular vestibule. ${ }^{[10]}$

Facial artery is selected as a target for superselective intraarterial chemotherapy during the treatment of some cancers of the head. ${ }^{[11]}$

The present study is conducted to find the variations of facial artery branches, the presence of premasseteric branch, and frequency of enlarged transverse facial artery and also to note the diameter of facial artery to insert the canula of appropriate diameter.

\section{Materials and Methods:}

Fifty formalin-fixed hemi-faces of adult cadavers ( 38 males and 12 females) were dissected meticulously following the Cunningham's manual of practical anatomy, volume 3 . The age of the cadavers was not noted. Course, main branches and termination of facial artery on face was noted and photographed.Diameter of facial artery was noted at two regions, namely at the point of its origin and at the anteroinferior angle of masseter where it enters the face. The diameter was measured using fine microcaliper and expressed in millimeters. Gross variations in the arterial supply of face were also noted.

\section{Results:}

The variations in the facial artery were grouped under three categories following the classification of Bayram et.al, 2010. Type I category - Facial artery terminated as angular artery (Figure1); Type II category - facial artery terminated as superior labial (Figure2); Type III - Facial artery terminated as inferior labial (Figure 3). In the present study, Type III category was seen only in $2 \%$ of the hemifaces. The results are tabulated in Table 1. Premasseteric branch was observed in fourhemi-faces (two female and two male) (Figure 4) belonging to Type I category. A duplex with a prominent lateral angular branch was observed in four hemi-faces (Figure5) belonging to Type I category. Premasseteric branch was observed in one hemi-face belonging to Type II facial artery (Figure 2). In cases where facial artery belonged to Type III category, the transverse facial artery supplied major part of the face (Figure 3). This finding was observed unilaterally in two hemi-faces. Normally, the facial artery lies medial to the facial vein. But in one hemi-face, we have noted that the facial artery which belonged to the type III category crossed the superficial to the facial vein from posterior to anterior (Figure 3).

\section{Discussion :}

Facial artery may vary in its size, (diameter and length) and the area of face which it supplies. In case of its variation, arterial supply to the face may be furnished by branches of transverse facial artery and the arteries accompanying the cutaneous nerves of face. In the present study facial artery showed wide range of variation. The transverse facial artery was very prominent and supplied major part of face in two male hemi-faces.

Facial artery has been extensively studied by the previous 


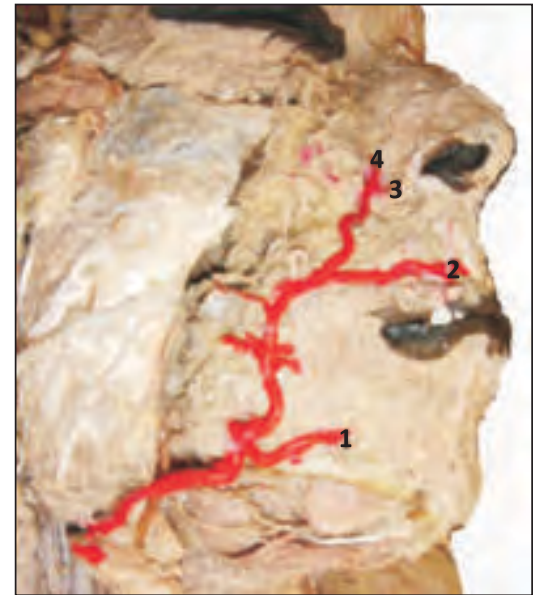

Figure 1 : Photograph of right hemi-face showing Type I category of facial artery. 1- Inferior labial artery, 2- Superior labial artery, 3Lateral nasal artery, 4- angular artery

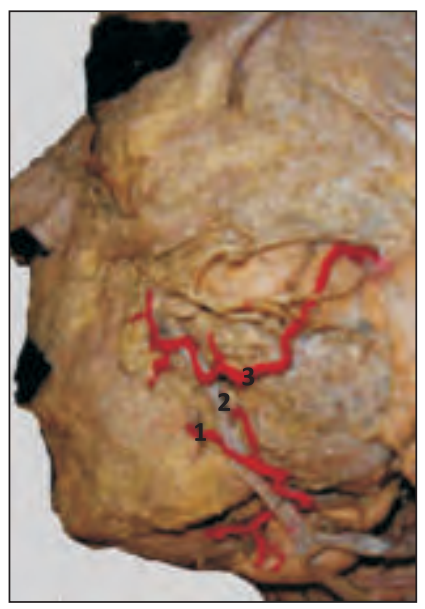

Figure 3 : Photograph of left hemi-face showing Type III category of facial artery. 1- Inferior labial artery, 2- Facial vein, 3- Transverse facial artery. Note the crossing of facial artery superficial to facial vein

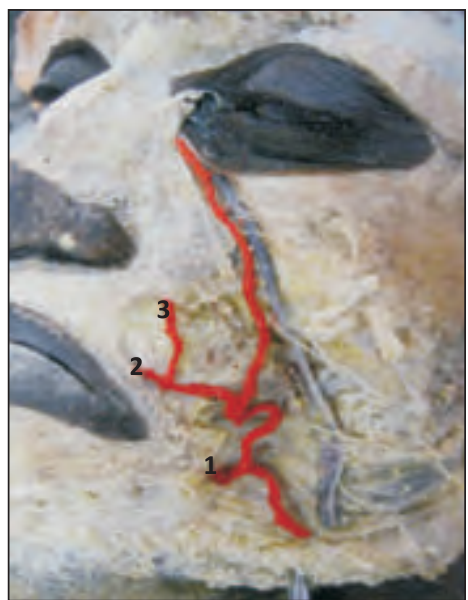

Figure 5 : Photograph of left hemi-face showing Type I category of facial artery with a duplex with prominent lateral nasal branch. 1Inferior labial artery, 2- Superior labial artery, 3- Lateral nasal artery, 4- lateral angular branch

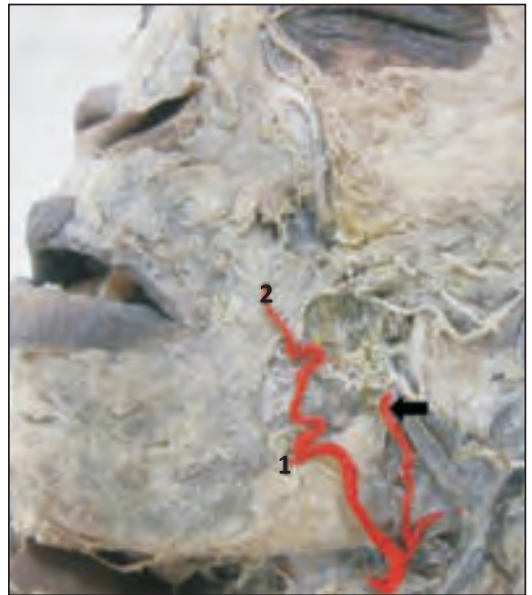

Figure 2: Photograph of left hemi-face showing Type Il category of facial artery. 1- Inferior labial artery, 2- Superior labial artery, arrow- premasseteric branch of facial artery

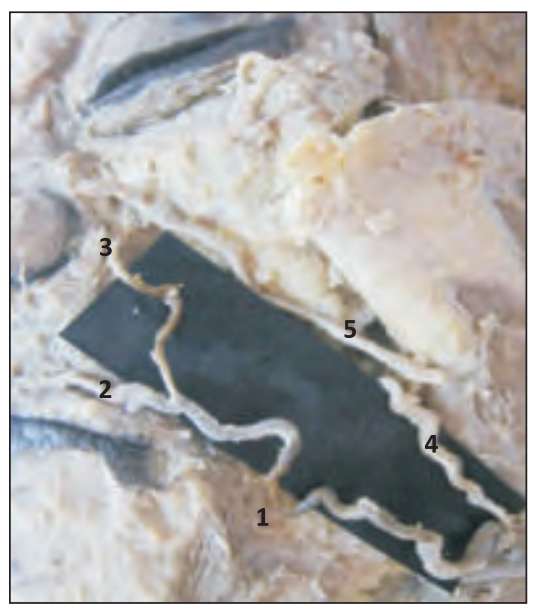

Figure 4 : Photograph of left hemi-face showing Type I category of facial artery. 1- Inferior labial artery, 2- Superior labial artery, 3lateral nasal artery, 4- premasseteric branch, 5- Facial vein

authors. Loukas et.al (2006) ${ }^{[3]}$ studied the variations of facial artery with special emphasis on superior labial artery in 284 hemi faces and observed five categories of facial artery terminations labeled A through E. In Type A- facial artery terminated by bifurcating into superior labial and lateral nasal arteries (47.5\%); in Type B-facial artery terminated as superior labial and lateral nasal with the lateral nasal continuing as superior alar artery (38.7\%); in Type C- facial artery terminates as superior labial artery (8.4\%); in Type D- angular artery arises directly from facial arterial trunk rather than as a termination of lateral nasal, with the facial artery ending as superior alar artery (3.8\%); in Type E- facial artery terminated as a rudimentary twig without providing any significant branches (1.4\%). In our study, Type II 
category is equivalent to Type Cand was observed in $18 \%$ of female left hemi-faces. Type D was also observed in two hemi-faces which were grouped under Type I category in the present study.

Bayram et.al $(2010)^{[2]}$ observed variations of facial artery in fetuses. He found Type I facial artery in 76\%, Type II category in $12 \%$ and Type III category in $12 \%$ of hemi-faces. In our study, Type I category (including the pre-masseteric and duplex with dominant lateral nasal branches) was observed in 94\%, Type II was observed in $2 \%$ and Type III category was observed in $4 \%$.

Niranjan NS (1988) ${ }^{[12]}$ observed the variations of facial artery in 50 hemi-faces. According to him, facial artery terminated as angular artery in $68 \%$ of hemi-faces, lateral nasal artery in $26 \%$ of hemi-faces, Superior labial artery in $4 \%$ of hemi-faces and $2 \%$ terminated at the alar base. In the present study, termination of facial artery as angular artery was seen in $94 \%$ of hemi-faces and termination as superior labial artery was seen in $2 \%$ of hemi-faces which was almost equivalent to his study.

Premasseteric branch of facial artery was first described by Adachi in $1928{ }^{[4]}$ This branch ascends along the anterior border of masseter accompanied by the facial vein. In the present study, out of fifty hemi-faces, premasseteric branch was quite large and prominent in four hemi-faces belonging to Type I category and one hemi-face belonging to Type II facial artery.

Kumar $\mathrm{N}$ et.al $(2011)^{[13]}$ stated that the premasseteric branch is likely to be injured causing severe bleeding during maxillofacial surgeries. This artery may compress upon the facial vein or parotid duct where it crosses them. The masseter muscle is often exploited by craniofacial surgeons without the knowledge of the occurrence of premasseteric branch of facial artery.

According to a study conducted by Magden et.al $(2009)^{[5]}$, on the premasseteric branch, out of 27 cases, in $3 \%$ cases the diameter of premasseteric branch was larger than the facial artery. In the present study, no such finding was observed. He has also studied the anastomosis of the premasseteric branch with the surrounding arteries. But in the present study, it was not done.

Gardetto et.al (2002) ${ }^{[14]}$ analyzed a cutaneous branch of facial artery, which was named as cutaneous zygomatic branch according to its topographical location. In the present study, no such branch wasfound.

In a study conducted by to Lohn et.al $(2011)^{[6]}$ on 201 facial arteries, suggested that, the facial artery predominantly terminated as lateral nasal artery in $49 \%$ of cases and facial artery was undetectable with transverse facial artery dominance in $5 \%$ cases.

In the recent years, facial artery has been used for intraarterial chemotherapy during the treatment of some cancers of the head. Therefore, in the present study, the diameters of the facial artery taken at two points may help the surgeons to select a canula of appropriate diameter.

A duplex with a dominant lateral angular branch was described by Loukas et.al (2006). ${ }^{[3]}$ He has categorized variations of the facial artery from Type $A$ through Type $E$. Subtypes were observed in Type A through Type C (A: 1-7: B: 1-4; C: 1-3). In the present study, Type A3 was seen in four hemi-faces (bilaterally in one case) (Figure 5), in which facial artery bifurcated into angular and superior labial arteries, the latter giving off the lateral nasal artery.

\section{Conclusion :}

Our main aim in this study was to equip the surgeons, oncologists and academicians of the possible variations in the facial artery branches which would help in avoiding the mishaps during certain surgical procedures such as facelift operations, and may contribute to the ease and speed when performing the surgeries and also provide a confident approach to the plastic surgeons to perform reconstructive procedures in this region in order to increase the cosmetic value of an individual. 


\begin{tabular}{|l|l|c|c|c|}
\hline & & Type I & Type II & Type III \\
\hline \multirow{2}{*}{ Male $(\mathrm{n}=38)$} & Right side & $100 \%$ & 0 & 0 \\
\cline { 2 - 5 } & Left side & $78 \%$ & 0 & $22 \%$ \\
\hline \multirow{2}{*}{ Female $(\mathrm{n}=12)$} & Right side & $80 \%$ & 0 & $20 \%$ \\
\cline { 2 - 5 } & Left side & $80 \%$ & $18 \%$ & $2 \%$ \\
\hline
\end{tabular}

Table 1 : Incidence of branches of facial artery on face

\begin{tabular}{|c|c|c|c|c|c|c|c|}
\hline \multicolumn{4}{|c|}{ Male } & \multicolumn{4}{|c|}{ Female } \\
\hline \multicolumn{2}{|c|}{ Right side $(n=19)$} & \multicolumn{2}{|c|}{ Left side $(n=19)$} & \multicolumn{2}{|c|}{ Right side $(n=6)$} & \multicolumn{2}{|c|}{ Left side $(n=6)$} \\
\hline At origin & At antero-inferior & At origin & At antero-inferior & At origin & At antero-inferior & At origin & At antero-inferior \\
\hline & angle of masseter & & angle of masseter & & angle of masseter & & angle of masseter \\
\hline 3.2 & 3.0 & 3.1 & 2.8 & 3.0 & 2.6 & 3.2 & 2.6 \\
\hline
\end{tabular}

Table 2 : Average diameter of facial artery at its origin and antero-inferior angle of masseter in millimeters

\section{References:}

1. G.J.Romans. Cunningham's manual of practical anatomy. $15^{\text {th }}$ ed. New York: Oxford medical publications; 2003.

2. Bayram SB, Kalaycioglu A. Branching patterns of facial artery in fetuses. The New Journal of M edicine.2010;27:227-30.

3. Loukas M, Hullet J, Louis RG Jr, Kapos T, Knight J, Nagy R, et al. A detailed observation of variations of the facial artery, with emphasis on the superior labial artery.SurjRadiol Anat. 2006;28(3):316-24.

4. Adachi B. Arteriensystem der Japaner. Band I, Kyoto, Verlag der Kaiserlich-JapanischenUniversitatzu Kyoto. 1928;73-7 (Japanese).

5. Magden O, Gocmen-mas N, Senan S, Edizer M, Karacayli U, Karabekir HS. The premasseteric branch of facial artery: Its importance for craniofacial surgery. Turkish Neurosurgery. 2009;19(1):45-50.

6. Lohn JW, Penn JW, Norton J, Butler PE. The course and variation of the facial artery and vein: implicatons for facial transplantation and facial surgery. Ann PlastSurg, 2011;67(2):184-8.

7. Tubbs RS, Salter EG, Oakes WJ. Unilateral agenesis of the facial artery with compensation by a giant transverse facial artery. Folia M orphol (Warsz). 2005: 64(3):226-8.

8. Pribaz J, Stephens W, Crespo L, Gifford G. A new intra oral flap: facial artery musculomucosal (FAMM) flap. PlastReconstr Surg. 1992;90(3):421-9.

9. DupoirieuX L, Plane L, Gard C, Penneau M . Anatomical basis and results of the facial artery musculomucosal flap for oral reconstruction. $\mathrm{Br}$ J Oral M axillofac Surg. 1999;37(1):25-8.

10. Hatoko M, Kuwahara M, Tanaka A, Yurugi S. Use of facia artery musculomucosal flap for closure of soft tissue defects of the mandibular vestibule. Int J Oral M axillofac Surg. 2002,31(2):210-11.

11. Shimizu T, Sakakura Y, Hattori T, Yamaguchi N, Kubo M, Sakakura K. Superselectiveintraarterial chemotherapy in combination with irradiation: preliminary report. Am J Otolaryngol. 1990;11(2):131-6.

12. Niranjan NS. An anatomical study of the facial artery. Ann Plast Surg. 1988:21(1):14-22.

13. Kumar N, Nayak SB, Shetty S, Guru A. Unusual posterior (premasseteric) branch of facial artery - a case report. IJAV. 2011;4:161-3.

14. Gardetto A, M origgl B, M aurer H, Erdinger K, Papp C. Anatomical basis for a new island axial pattern flap in the perioral region. SurgRadiolAnat, 2002;24(3-4):147-54. 